\title{
APPLICATION OF GFRP REINFORCEMENT IN THE DESIGN OF CONCRETE STRUCTURES AND ITS EXPERIMENTAL EVALUATION
}

\author{
Katarína Gajdošová ${ }^{*}$ - Viktor Borzovičำ Adrián Valašík ${ }^{1}$ - Natália Gažovičová ${ }^{1}$
}

\begin{abstract}
In the past, research on the use of FRP in civil engineering has been focused on strengthening existing structures where FRP reinforcements were applied to the surface of concrete elements. Recently, the application of FRP reinforcements has been studied to replace steel reinforcements for use in areas of increased environmental loads, with a need to exclude the corrosion of the reinforcement or to ensure the electromagnetic neutrality of the individual elements of the load-bearing structure. The GFRP reinforcement ratio was verified considering failure modes in flexure and the bond of the GFRP reinforcement with concrete. Besides classical reinforcements, GFRP has also been used in prestressed variants, and the possibility of its use as permanent formwork has been verified. In terms of extending the use of non-metallic reinforcements, it is important to note the long-term exposure and possible degradation of the mechanical properties.
\end{abstract}

\section{Address}

1 Slovak University of Technology, Faculty of Civil Engineering, Dept. of Concrete Structures and Bridges, Bratislava, Slovakia

* Corresponding author: katarina.gajdosova@stuba.sk

\section{Key words}

- Non-metallic reinforcement,

- GFRP,

- Flexure,

- Bond of GFRP reinforcement,

- Prestressing of GFRP,

- Long-term properties.

\section{INTRODUCTION}

Fiber Reinforced Polymer (FRP) composites can be used as a replacement for steel reinforcements when designing new structures; they are especially used in renovations, since adding them to the surface of concrete elements does not significantly increase the cross section of the element.

Compared to steel reinforcements, the initial material costs are higher, which in many cases can discourage the investor. Over the lifetime of the reinforcement the negatives of high starting costs are reduced due to the low maintenance costs that need to be spent during the structure's operation. There are also some applications where a steel reinforcement may not even be used. Examples include elements subjected to a high environmental load or elements for which special requirements are requested, non-conductive materials, or materials not affecting the magnetic field. In addition, FRP composites provide many other advantages, i.e., high resistance to aggressive chemicals, a significantly higher tensile strength compared to steel reinforcements, less weight, and elimination of the minimum requirement for a concrete cover for durability (but the cover requirement is necessary to be assessed in terms of fire resistance). In this paper, the research focused on the GFRP reinforcement ratio, the bond of the GFRP reinforcement with concrete, prestressed variants of GFRP, and possible degradation of the mechanical properties during the long-term exposure are presented.

\section{BENDING RESISTANCE OF CROSS SECTIONS REINFORCED WITH GFRP}

The first part of the experimental investigation was inspired by the idea of replacing steel reinforcements with Glass Fiber Reinforced Polymer (GFRP) by a simple change that was derived based on the approximate equivalence of the tensile resistance of the steel and composite reinforcement (e.g., steel $\varnothing 10 \mathrm{~mm} \rightarrow$ GFRP $\varnothing 8 \mathrm{~mm}$, steel $ø 14 \mathrm{~mm} \rightarrow$ GFRP $\varnothing 12 \mathrm{~mm}$, etc.). At first sight, the tensile strength- 
a)

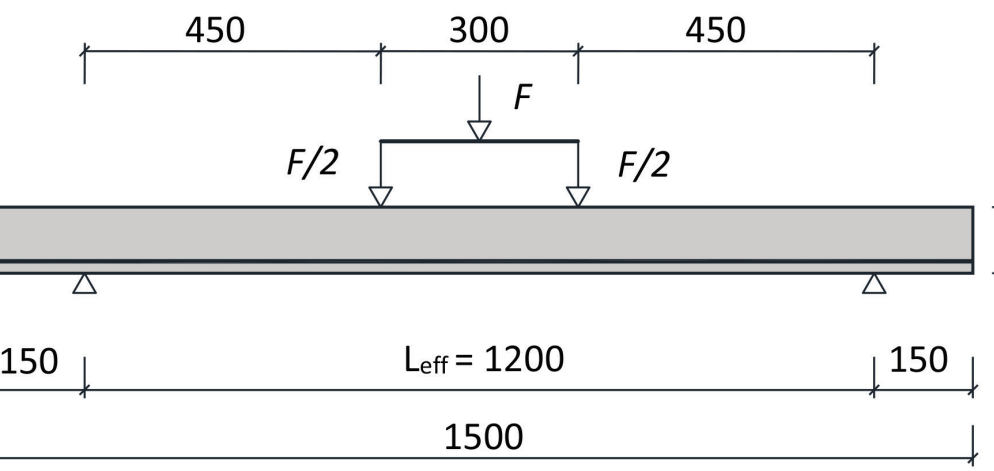

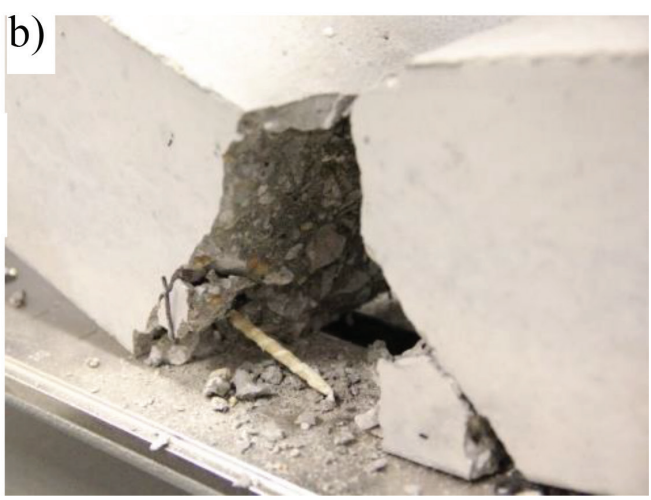

Fig. 1 Scheme of the loading test for determining the bending resistance (dimensions in $\mathrm{mm}$ ) (a) and the beam of the first series after failure (b)

a)

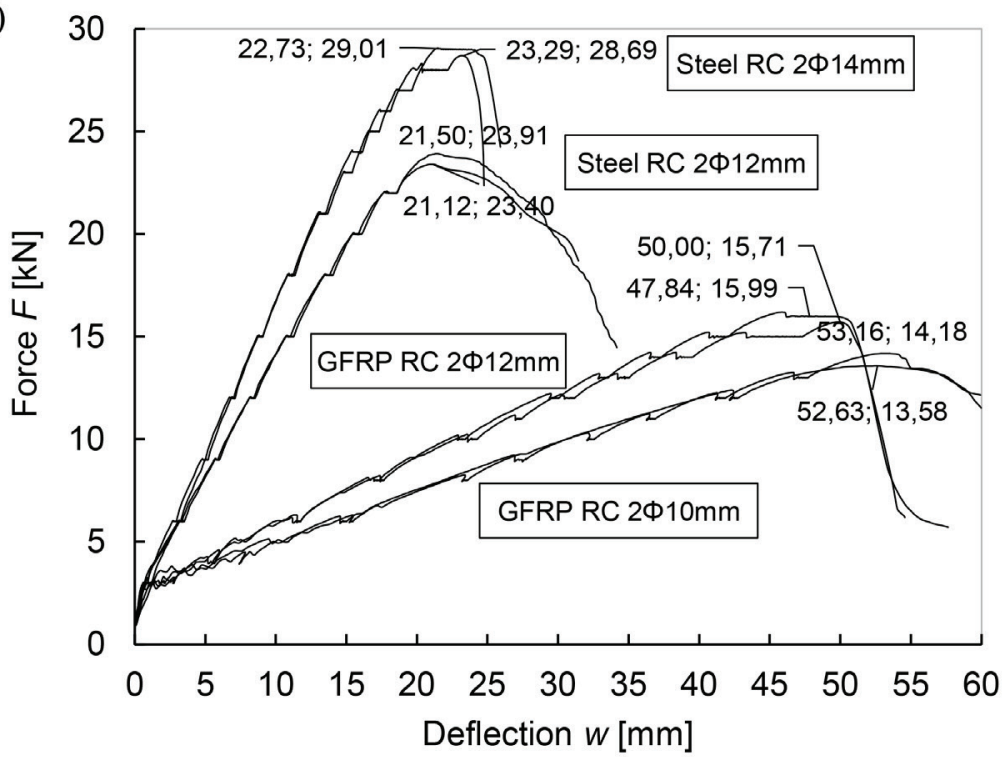

b)

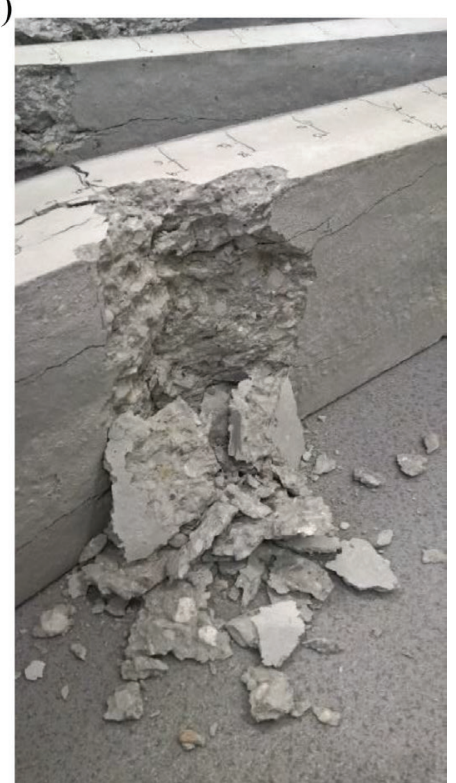

Fig. 2 Force - deflection diagram of the loading test of the beams of the second series with steel reinforcements of $\varnothing 12 \mathrm{~mm}$ and $\varnothing 14 \mathrm{~mm}$ and GFRP reinforcements of $ø 10 \mathrm{~mm}$ and $ø 12 \mathrm{~mm}(\mathrm{a})$, and the characteristic details of the failure (b)

based equivalence seems to be correct for calculating the bending resistance. The approach for determining the bending resistance differs, however, considering the lack of plastic behavior of GFRP compared to a steel reinforcement.

A total of 6 beams with a length of $1.5 \mathrm{~m}$ and cross-sectional dimensions of $100 \times 100 \mathrm{~mm}$ were tested in the first series. The concrete cover was $15 \mathrm{~mm}$ for all the specimens. The steel reinforced beams had 2 bars with a $6 \mathrm{~mm}$ diameter (a reinforcement ratio of $0.57 \%$ ); the GFRP reinforced beams had 2 ribbed-surface bars with a $4 \mathrm{~mm}$ diameter (a reinforcement ratio of $0.21 \%$ ). The beams were subjected to a four-point load test (Fig. 1a). The failure of the GFRP-reinforced beams occurred at a force representing $41 \%$ of the resistance of the steel-reinforced specimens. The first loading steps of the GFRP-reinforced beams induced a large crack that rapidly developed along the height of the concrete section; a collapse of the beam subsequently occurred due to the splitting of the bar. The reinforcement ratio of the beams was close to the so-called balanced reinforcement ratio, which assumes a beam's failure in bending due to the collapse of the reinforcement. Considering the lever arm of the reinforced cross section at a level of $90 \%$ of the effective height, the stress in the GFRP bar reached a value of about 800 to $900 \mathrm{MPa}$ at the moment of failure (calculated value). A characteristic effect of the failure of beams with a GFRP reinforcement in the first series was that the reinforcement bar's rupture did not appear in the section where the crack was. Upon the collapse the beams broke into two pieces, and, from the point of the beam's failure (Fig. 1b), the GFRP reinforcement was sticking out approximately $50 \mathrm{~mm}$ from the crack. This mode of failure suggests bond problems resulting from a large difference in stiffness between the cracked and non-cracked sections.

In the second series 8 beams were tested. The specimens were once again $1.5 \mathrm{~m}$ long with cross-sectional dimensions of $175 \mathrm{~mm}$ in width and $75 \mathrm{~mm}$ in height. The concrete cover was $15 \mathrm{~mm}$. Two steel-reinforced beams were reinforced with two bars of a diameter of $12 \mathrm{~mm}$ (a reinforcement ratio of $2.4 \%$ ), and another two beams were reinforced with two bars with a diameter of $14 \mathrm{~mm}$ (a reinforcement ratio of $3.3 \%$ ). Two other beams were reinforced with GFRP reinforcements with a diameter of $10 \mathrm{~mm}$ (a reinforcement ratio of $1.5 \%$ ) and two beams with a GFRP reinforcement with a diameter of $12 \mathrm{~mm}$ (a reinforcement ratio of $2.3 \%$ ). The results of the experimental measurements are presented in Figure 2a. The beams with the GFRP reinforcement showed greater deflections even when loaded with a lower force than the steel-reinforced beams.

The failure of the beams reinforced with the GFRP reinforcement with an equivalent reinforcement ratio occurred at a force with 
a level of about $57 \%$ of the resistance of the beams with a steel reinforcement.

The reinforcement ratio of the GFRP-reinforced beams of the second series was higher than the balanced reinforcement ratio. Flexural failure was attained due to the crushing of the concrete in the compression zone; therefore, the rupture of the GFRP did not occur. Details of the characteristic failure of GFRP-reinforced beams of the second series are shown in Figure $2 b$.

Based on these results, it can be stated that the behavior of GFRP reinforcements in concrete members subjected to bending differs considerably from members reinforced with steel, especially at lower values of the reinforcement ratio. When beams reinforced with GFRP reinforcement were loaded, a dominant crack was observed, which extended right after its formation and quickly attained a width greater than $0.3 \mathrm{~mm}$. This was caused by the modulus of elasticity, which is four times lower than the modulus of elasticity of the steel reinforcement. The serviceability limit state seems to be a particularly important factor in the design of concrete members reinforced with composite reinforcements. The application of GFRP could be used in parking lots, highway bridges, and places where conventional reinforced concrete structures suffer from aggressive properties of the local environment. In order to avoid a failure due to fragility, it is necessary to limit the tension in the GFRP reinforcement when designing it and also ensure the maximum crack width and deflection, which can lead to a considerably increased reinforcement ratio. With a higher reinforcement ratio, the behavior of beams reinforced with GFRP and steel is already similar. In this case, a less ductile mode of failure based on the failure of concrete in a compression zone becomes the main deficiency. During the experimental verification, the failures were sudden and without any prior notice (Lániová et al., 2017).

\section{BOND OF A GFRP REINFORCEMENT IN CONCRETE}

Ensuring the behavior of the bond between a GFRP reinforcement and concrete is a basic requirement for designing concrete members reinforced with composite materials. The load transfer method between the concrete and reinforcement affects the behavior of the structure, especially the widths and distances of cracks, deflections, anchoring lengths, and the minimum thickness of the cover layer. The bond between the GFRP reinforcement and concrete is ensured by friction and possibly by the mechanical interlocking of the modified reinforcement surface. The mechanical interlocking is significant for steel reinforcements, which is the main difference (Bilčík et al., 2015). For a GFRP reinforcement the main part of the bond belongs to friction, the effect of which is increased by roughening the surface. The other factors affecting the bond between a GFRP reinforcement and concrete are the shape of the surface and the mechanical properties of the reinforcement, the diameter of the reinforcement, the compressive strength of the concrete, the anchoring length, and the confinement of the reinforcement.

Several test methods are used to determine the characteristics of the bond between a reinforcement and concrete. For a GFRP reinforcement, two types of bond tests are used, i.e., pull-out tests and beam tests. These tests are conceptually inconsistent in the results achieved. The bond stress obtained from the beam tests is usually lower than that of the pull-out tests.

The experimental program includes pull-out tests of a GFRP reinforcement with a diameter of $16 \mathrm{~mm}$ and with a ribbed-surface. Specimens were tested in two series, i.e., 3 and 28 days after the concreting. The GFRP reinforcement was pulled out of a cube with dimensions of $200 \mathrm{~mm}$. Part of the GFRP reinforcement embedded in the concrete was separated from the concrete by a plastic pipe (on the pulled side) to prevent a vault effect on the bond. The anchorage length of the GFRP reinforcement in the concrete was five times the diameter of the reinforcement. The arrangement of the pull-out test is shown in Figure 3. A steel frame was constructed for the test, which was placed in a press machine with a capacity of $100 \mathrm{kN}$. The displacement of the GFRP reinforcement at its free end was measured with a linear variable differential transformer. The load was applied at a rate of $1.2 \mathrm{~mm} / \mathrm{min}$.

The results from the experimental investigation show the effect of the age (and therefore the strength) of the concrete on the ratio between the bond stress and the slip of the GFRP reinforcement on its unloaded end. The bond of the 28-day specimens is transmitted by the mechanical interlocking of the ribs created by confining the reinforcement. Once the maximum bond stress has been reached, the a)

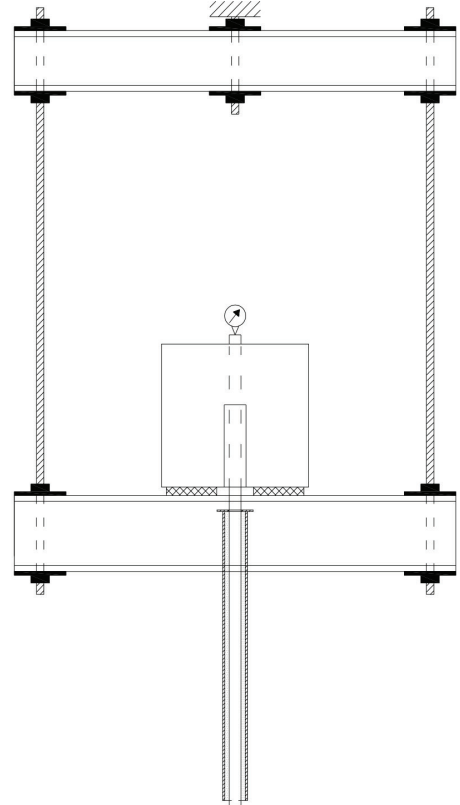

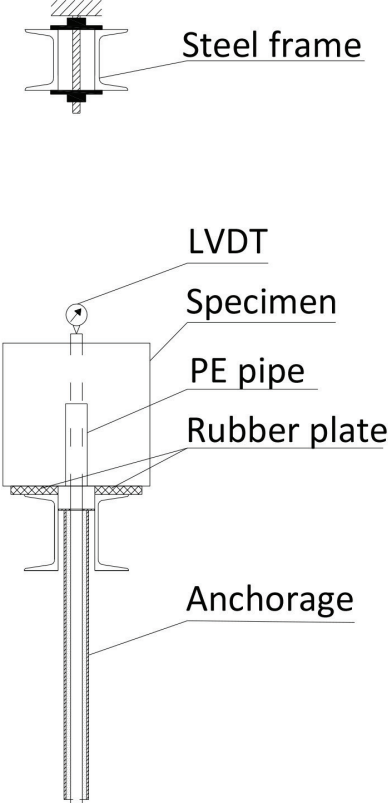
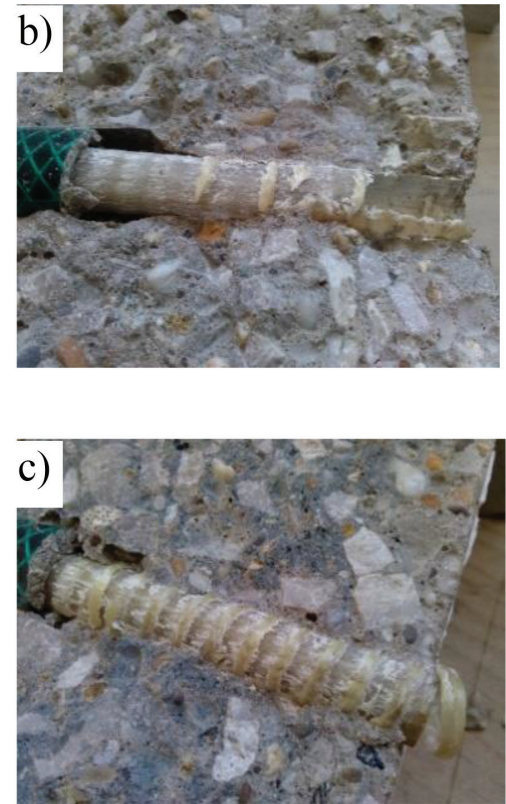

Fig. 3 Arrangement of the pull-out test (a) and specimens after failure (3-day specimen (b) and 28-day specimen (c)) 


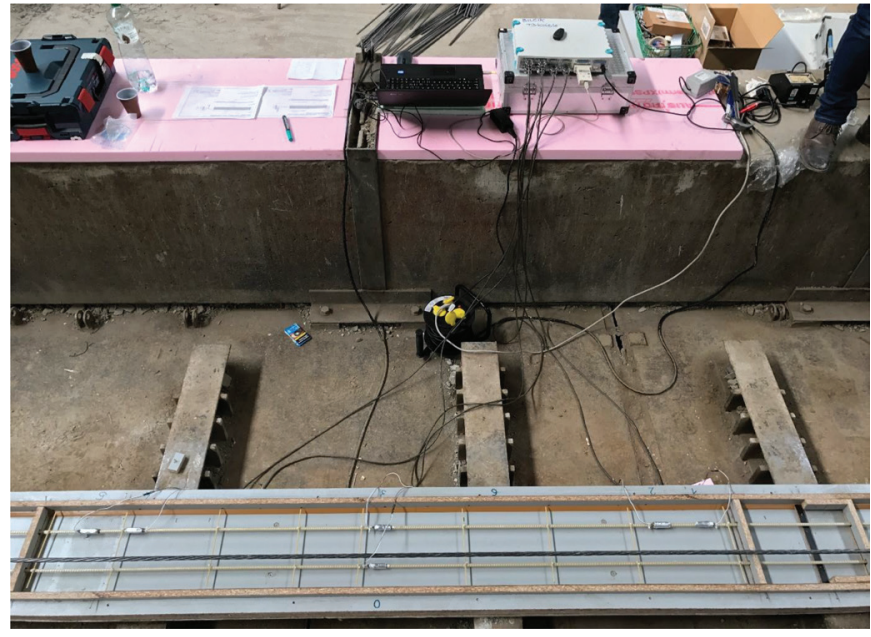

Fig. 4 Measurement of the relative strains of the GFRP reinforcement during pre-tensioning

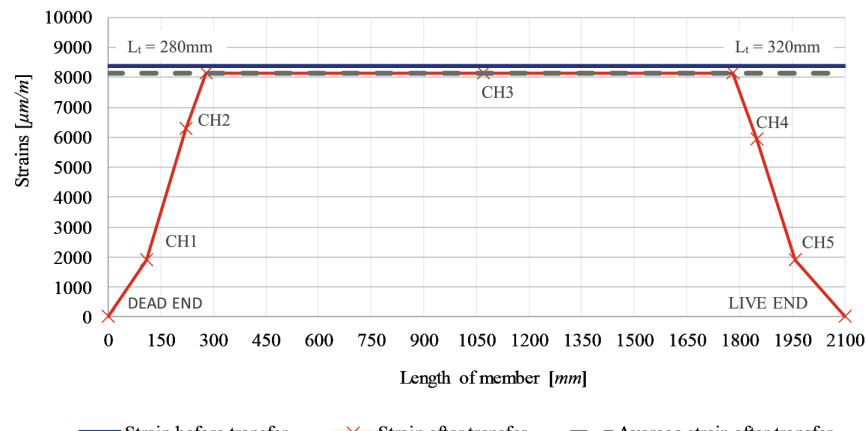

Fig. 5 Measured strains of GFRP reinforcement alongside the element

bond is only transmitted by friction. The bond of the 3-day specimens only consists of the mechanical interlocking of the reinforcement ribs. The failure of the 28-day specimens occurred by cutting the modified reinforcement surface (cutting of the ribs). The surface layer of the fibers of the GFRP reinforcement was peeled off on the 3 -day specimens. The failure of the concrete from being crushed between the reinforcement ribs did not occur in either case.

Higher values of bond stresses are greatly increased by the effect of mechanical interlocking; the radial component of the bond force is in an equilibrium with the radial stress from the transverse strain of the concrete. As a result, concrete causes the confinement of the reinforcing bar. Young concrete cannot ensure a thorough confinement of the reinforcement, so the 3-day tests $(12 \mathrm{MPa})$ did not reach the maximum bond stress of the 28-day specimens (15 MPa) (Gažovičová et al., 2018).

\section{PRESTRESSED GFRP REINFORCEMENT IN LOST FORMWORK}

Reduced requirements for the thickness of concrete cover due to non-corrosivity make it possible to use a GFRP reinforcement to produce very slender concrete elements. One of these applications is reinforcing the elements of lost formwork with GFRP. In the next part of our experimental investigation, the prestressing of the GFRP reinforcement was verified in thin slabs for the lost formwork. The prestressing in these slabs has the advantage in the possibility of reduction of the final deflection.
The concrete slab, which was to be used as lost formwork without any further supporting function, was designed with a thickness of $40 \mathrm{~mm}$ and reinforced with 2 bars of a GFRP reinforcement with a diameter of $10 \mathrm{~mm}$. The slab dimensions were $2060 \times 500 \times 40 \mathrm{~mm}$; the concrete cover was $10 \mathrm{~mm}$. The $\mathrm{C} 35 / 45$ concrete class was chosen.

The slabs were designed for short-term loads from the self-weight of the fresh concrete with a thickness of $250 \mathrm{~mm}$ and one worker with a weight of $100 \mathrm{~kg}$. According to research on long-term stress on the reinforcement of precast prestressed beams, the maximum limit value of the stress for a reinforcement at the time of prestressing was set at $534 \mathrm{MPa}$, which corresponds to $43.5 \%$ of the characteristic value of the tensile strength; the limit of the tensioning force was $34 \mathrm{kN}$. The prestressing of the GFRP reinforcement was realized in three phases. The first level of the prestressing force was at $11 \mathrm{kN}$, the second level at $22 \mathrm{kN}$, and finally the full value of the prestressing force was at 34 $\mathrm{kN}$. The prestressing for the GFRP reinforcement process was followed by the pouring of the concrete.

Based on the known position of the strain gauges and the values of the GFRP reinforcement strains at the time before and after the prestressing transfer, it was possible to evaluate the length of the transfer, which is necessary for the transfer of the pre-stressing force into the element. The increase in the prestressing force over the length of the element was considered to be linear. On that basis it was possible to determine the transfer length of $280 \mathrm{~mm}$ for the dead end and $320 \mathrm{~mm}$ for the live end with the use of a graphic evaluation (Valašík, 2017).

\section{LONG-TERM PROPERTIES}

The mechanical properties of a FRP reinforcement significantly change over time. To date, there is not enough information about the long-term behavior of FRP reinforcements, because they have not been used for a long period of time and because structures with FRP reinforcements or strengthening systems have not yet reached their service life.

According to various standards, the long-term properties of FRP reinforcement are calculated from short-term properties by the introduction of reduction factors ( $f i b, 2007)$. Properties reduced according to these requirements are very low, and the use of an FRP reinforcement does not seem to be effective. It has to be stated that reduction factors for long-term properties have not yet been measured experimentally; they have only been extrapolated over time from shortterm tests. The experimental investigation on structures with FRP reinforcements subjected to a sustained load for almost ten years does not contribute to these assumptions (Kemp and Blowes, 2011; Deza and Nanni, 2005; Sasaki and Nishizaki, 2010).

The main factor causing the limit usage of an FRP reinforcement is its creep rupture. An FRP reinforcement subjected to a constant load over time can suddenly fail after a time period known as the "endurance time". This phenomenon is known as "creep rupture". The endurance time of an FRP reinforcement decreases as the ratio of the sustained tensile stress to the short-term strength increases. The endurance time also decreases with the effects of high temperatures, ultraviolet radiation exposure, high alkalinity, wet and dry cycles, and freezing-thawing cycles (ACI 440.1R-03). Carbon fibers have a very good resistance to creep rupture. Aramid fibers are more susceptible to this phenomenon, and glass and basalt fibers are the most susceptible. Nevertheless, the susceptibility of resin is the greatest problem.

The viscoelastic response and temperature sensitivity of polymeric resins make an FRP material more sensitive to creep and other rate-dependent phenomena than metallic materials. A few series of creep rupture tests have been conducted on FRP reinforcements with different fibers (carbon, aramid, glass, basalt). The tests have usually lasted for $100 \mathrm{~h}$, and the results were linearly extrapolated 
to $500,000 \mathrm{~h}$ (more than 50 years). The results of the experimental programs are summarized in Table 1. These studies show that glass and basalt fiber-reinforced polymers have a very low resistance to long-term loading.

Tab. 1 Long-term stress limitation factors (fib, 2007)

\begin{tabular}{|l|c|c|c|c|}
\hline & CFRP & GFRP & AFRP & BFRP \\
\hline ACI 440.1R-06 & $0.55 f_{\mathrm{fu}}$ & $0.20 f_{\mathrm{fu}}$ & $0.30 f_{\mathrm{fu}}$ & - \\
\hline Yamaguchi et al. (1997) & $0.93 f_{\mathrm{fu}}$ & $0.29 f_{\mathrm{fu}}$ & $0.47 f_{\mathrm{fu}}$ & - \\
\hline Ando et al. 1997 & $0.79 f_{\mathrm{fu}}$ & - & $0.66 f_{\mathrm{fu}}$ & - \\
\hline Seki et. al (1997) & - & $0.55 f_{\mathrm{fu}}$ & - & - \\
\hline Banibayat and Patnaik (2014) & - & - & - & $0.18 f_{\mathrm{fu}}$ \\
\hline
\end{tabular}

* $f_{\mathrm{fu}}$ is the tensile strength of FRP reinforcement

With FRP composites, it is generally necessary to address the issue of durability as various environmental influences significantly affect their properties. Several studies in recent years have focused on changes in the mechanical properties of FRP composites after long-term exposure to environmental influences. Based on these facts, environmental impact reduction factors have been introduced in some countries to limit the mechanical properties of FRP composites (ranging from 0.95 for CFRP to 0.5 for GFRP). Reducing tensile strength due to these effects results in a significant reduction in the final cross-section resistance of an FRP-reinforced structural member. Using the example of a simple one-way slab (Gajdošová and Sonnenschein, 2017), it can be seen that the reduction of the cross-section resistance is in a range of $5-50 \%$ for durability and $20-90 \%$ for additional long-term properties, depending on the type of FRP reinforcement used.
Nevertheless, it cannot be stated that FRP composites will not reliably satisfy their function in the structure and that structures with FRP reinforcement will fail before reaching their service life because the values of residual stresses are only extrapolated from short-term tests. We need actual experience over time to determine the true longterm degradation of these materials (Gajdošová and Sonnenschein, 2017).

\section{CONCLUSIONS}

FRP reinforcements are used in both civil engineering and building structures, either in the form of the reinforcement of new structures or in renovations. Slabs, beams and columns are reinforced with composite materials. Slabs are strengthened for flexure and punching, beams for flexure and shear, and columns for a combination of compression and flexure. Extending the use of composite materials is particularly hampered by the absence of standard procedures for designing new and strengthened structural members in our country and the lack of awareness of designers.

The stated examples showing the application of FRP reinforcements are evidence that properly specified FRP composites are a suitable replacement for steel reinforcements. Both research on and applications of FRP composites are becoming more and more widely deployed throughout the world; by introducing international standard procedures for their design, FRP composites can become an alternative equivalent to both classical and prestressing steel reinforcements.

\section{Acknowledgements}

This work was supported by the Slovak Research and Development Agency under Contract No. APVV-15-0658 and the University Science Park (USP) of the Slovak University of Technology in Bratislava (ITMS: 26240220084).

\section{REFERENCES}

Bilčík, J. - Gažovičová, N. - Hollý, I. (2015) Design principles and details. In Manual for designing GFRP reinforcements for concrete structures, Bratislava: Slovak Chamber of Civil Engineers, pp. $58-65$.

Deza, U. - Nanni, A. (2005) Performance Evaluation of a Short Span Bridge Built with FRP Reinforced Concrete Panels, ACI Special Publication, pp. 1191 - 1208.

fib Bulletin 40 (2007) FRP reinforcement in RC structures.

Gajdošová, K. - Sonnenschein, R. (2017) Endurance limit of FRP composites used for reinforcement of concrete structures. In Engineering Mechanics 2017. 23 $3^{\text {rd }}$ international conference. Svratka, Czech Republic. Brno: Brno University of Technology, pp. 322-325. ISSN 1805-8248. ISBN 978-80-214-5497-2.

Gažovičová, N. - Bilčík, J. - Hollý, I. - Halvoník, J. (2018) Bond behaviour between GFRP reinforcement and concrete using pullout test. In: Solid State Phenomena: 24 ${ }^{\text {th }}$ Concrete Days 2017. Vol. 272, pp. 232-237. ISSN 1012-0394.
Kemp, M. - Blowes,D. (2011) Concrete reinforcement and glass fiber reinforced polymer. Queensland roads edition no ii September 2011.

Lániová, D. - Švachula, R. - Borzovič, V. - Halvoník, J. (2017) Experimental verification of the action of GFRP reinforced beams. (in Slovak) In: Rehabilitation of concrete structures: Proceedings from the $10^{\text {th }}$ workshop. Smolenice, SR, 7. - 8. 12. 2017. Bratislava: IRIS, pp. 105-110. ISBN 978-80-8200-014-9.

Sasaki, I. - Nishizaki, I. (2010) Load-bearing properties of an FRP bridge after nine years of exposure. In Proceedings of the 5th international conference on FRP composites in civil engineering, CICE 2010, Beijing, China, 27-29 September.

Valašík, A. (2017) Prestressed slabs with GFRP reinforcement. (in Slovak) In: Juniorstav 2017: $19^{\text {th }}$ professional conference of doctoral studies. Brno: VUT in Brno, USB, ISBN 978-80-214-5473-6. 